\title{
Ceratoconjuntivite por Encephalitozoon hellem em periquitos agapornis (Agapornis spp.) no Brasil: relato de caso
}

[Keratoconjunctivitis by Encephalitozoon hellem in lovebirds (Agapornis spp.) in Brazil: case report]

\author{
A.A. Nakamura ${ }^{1}$, C.G. Homem ${ }^{2}$, S.D. Garcia ${ }^{3}$, M.V. Meireles ${ }^{3 *}$ \\ ${ }^{1}$ Aluno de pós-graduação - VPS-FMVZ-USP - São Paulo, SP \\ ${ }^{2}$ Aluna de pós-graduação - FOA-UNESP - Araçatuba, SP \\ ${ }^{3}$ Curso de Medicina Veterinária - FOA-UNESP - Araçatuba, SP \\ Rua Clóvis Pestana, 793 \\ 16050-680 - Araçatuba, SP
}

\begin{abstract}
RESUMO
Relata-se um caso de ceratoconjuntivite causada por Encephalitozoon hellem em agapornis (Agapornis spp.) adultos, provenientes de um criatório comercial. Cinco animais apresentaram sinais clínicos de ceratoconjuntivite, blefaroespasmo e blefaroedema bilateral, com presença de secreção seropurulenta. Amostras fecais foram colhidas e foi realizado exame coproparasitológico, com resultado negativo. Dois animais foram necropsiados, sendo detectados, em impressões de raspado de conjuntiva ocular, esporos e outros estádios evolutivos de Microsporidium. A confirmação do diagnóstico foi feita pela reação em cadeia de polimerase e sequenciamento de fragmentos amplificados, com utilização de primers específicos para o gene da subunidade $18 \mathrm{~S}$ do rRNA de E. hellem. A análise dos fragmentos amplificados demonstrou $100 \%$ de similaridade com outras sequências de E. hellem publicadas no GenBank. Este é primeiro relato de infecção por E. hellem em aves no Brasil.
\end{abstract}

Palavras-chave: Agapornis spp., ceratoconjuntivite, microsporidiose, Encephalitozoon hellem, zoonose

\begin{abstract}
A clinical case of keratoconjunctivitis by Encephalitozoon hellem in adult lovebirds (Agapornis spp.) from a commercial flock is reported. Five animals presented clinical symptoms of keratoconjunctivitis, blepharospasm, and bilateral blepharoedema, with seropurulent secretion. Coproparasitological diagnosis was carried out in fecal samples, with negative results. Two animals were necropsied, with detection of spores and other developmental stages of Microsporidium in conjunctival smears. The confirmation of the diagnosis was accomplished by the polimerase chain reaction with specific primers for $18 S$ subunit of the rRNA of E. hellem, followed by sequencing of amplified fragments, which revealed $100 \%$ of genetic similarity to E. hellem. This study is the first report of E. hellem infection in birds in Brazil.
\end{abstract}

Keywords: keratoconjunctivitis, microsporidiosis, Encephalitozoon hellem, Agapornis spp., zoonosis

\section{INTRODUÇÃO}

Microsporidium são organismos pertencentes ao filo Microspora, que engloba aproximadamente 100 gêneros e 1.200 espécies de parasitos eucarióticos intracelulares obrigatórios, encontrados em diversos hospedeiros, como mamíferos, anfíbios, répteis e aves (Mathis et al., 2005).

A primeira descrição de infecção por Encephalitozoon hellem foi realizada por Didier et al. (1991), que descreveram seu isolamento e caracterização em três pacientes humanos com a

Recebido em 27 de outubro de 2009

Aceito em 2 de agosto de 2010

*Autor para correspondência (corresponding author)

E-mail: marcelo@fmva.unesp.br 
síndrome da imunodeficiência adquirida associada a um quadro clínico de ceratoconjuntivite. Em psitacídeos, relatos prévios de infecção por microsporídios, semelhantes a Encephalitozoon, já haviam sido descritos, mas infecções por E. hellem só foram confirmadas recentemente, com auxílio de técnicas de biologia molecular (Mathis et al., 2005). O primeiro relato de infecção em periquitos australianos (Melopsittacus undulatus) foi feito por Black et al. (1997), que encontraram o parasito infectando o intestino, com taxas de mortalidade neonatal variando de 14 a $75 \%$.

Barton et al. (2003) descreveram a infecção em periquito agapornis (Agapornis spp.), com taxa de positividade de $25 \%$, em aves assintomáticas; Pilparampil et al. (1998) encontraram o agente em tecidos intestinal e renal de loris ecletus (Ecletus roratus). O organismo foi detectado ainda em suabe cloacal de lóris estriado (Chalcopsitta scintillata) e em um caso de enfermidade pulmonar e sistêmica em um papagaio de testa amarela (Amazona ochrocephala oratrix) (Snowden e Phalen, 2004).

Infecções intestinais ocasionadas por E. hellem já foram detectadas em agapornis (Agapornis spp.) (Snowden e Phalen, 2004), diamante de Gould (Cloebiae gouldiae) (Carlisle et al., 2002), em avestruzes (Struthio camelus) (Snowden e Logan, 1999) e em beija-flores (Calypte anna) (Snowden et al., 2001). Recentemente, Magalhães et al. (2006) encontraram positividade para E. hellem em star finch (Bathilda ruficauda), manon (Lonchura domestica), papagaio do congo (Psittacus erithacus), calopsita (Nymphicus hollandicus), periquito australiano (M. undulatus) e em pombo doméstico (Columba livia). Há apenas dois relatos de infecção ocular por E. hellem descritos em aves, um em um papagaio de testa amarela (A. o. oratrix) (Canny et al., 1999) e outro em uma cacatua alba (Cacatua alba) (Phalen et al., 2006).

O presente trabalho teve como objetivo descrever a ocorrência de ceratoconjuntivite por $E$. hellem em agapornis (Agapornis roseicollis, Agapornis personata e Agapornis fischeri) e alertar para o potencial de aves como reservatórios desse agente, para o risco zoonótico de sua transmissão e para que tal agente seja considerado no diagnóstico diferencial de ceratoconjuntivites resistentes às terapias antimicrobianas tradicionais.

\section{CASUÍSTICA}

Cinco aves exóticas adultas, pertencentes à família Psittacidae, gênero Agapornis, espécies A. roseicollis, A. personata e A. fischeri, provenientes de um criatório comercial situado na cidade de Araçatuba, São Paulo, foram encaminhadas ao Laboratório de Ornitopatologia do curso de Medicina Veterinária da UNESP, Campus de Araçatuba, apresentando quadro clínico de ceratoconjuntivite, blefaroespasmo, blefaroedema bilateral e secreção ocular seropurulenta (Fig. 1). A anamnese revelou histórico de tratamentos anteriores, realizados pelo proprietário, com utilização de colírios contendo polimixina $\mathrm{B}$, oxitetraciclina $\mathrm{e}$ neomicina, sem sucesso na resolução do quadro clínico. Nesse criatório, havia histórico recente de mortalidade de três aves (A. roseicollis), que também apresentavam ceratoconjuntivite. Durante visita ao estabelecimento, foi observado que havia três viveiros, o primeiro com $50 \mathrm{~A}$. roseicollis e A. personata, outro com $30 A$. fischeri e o último com $150 \mathrm{M}$. undulatus. Duas aves (A. personata e A. fischeri) apresentavam ceratoconjuntivite.

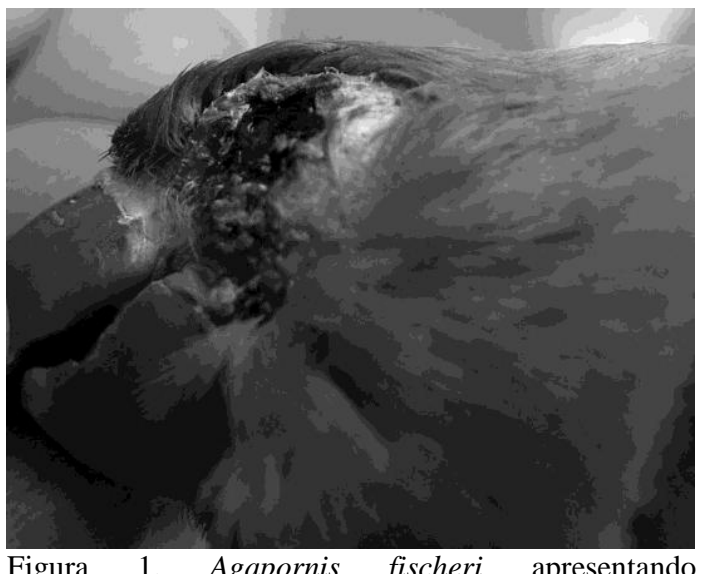
ceratoconjuntivite, blefaredema e blefaroespasmo bilateral com presença de secreção seropurulenta em olho esquerdo.

Amostras de fezes dos viveiros foram colhidas em frascos coletores universais de $100 \mathrm{~mL}$ e armazenadas sob refrigeração a $4^{\circ} \mathrm{C}$, sendo posteriormente submetidas a exame coproparasitológico, com utilização da técnica de 
centrífugo-flutuação em solução de Sheather (Current, 1990), observando-se ausência de nematódeos e protozoários. Duas aves que vieram a óbito foram necropsiadas, sendo observadas lesões macroscópicas caracterizadas por exsudato purulento na conjuntiva ocular, ceratite e atrofia de musculatura peitoral. O exame citológico foi realizado por meio de impressões de rins, fígado, intestino e raspado de conjuntiva ocular, corados com corante panótico rápido, sendo possível a detecção de esporos (Fig. 2) e outros estágios evolutivos de Microsporidium (Fig. 3) em raspados de conjuntiva ocular.

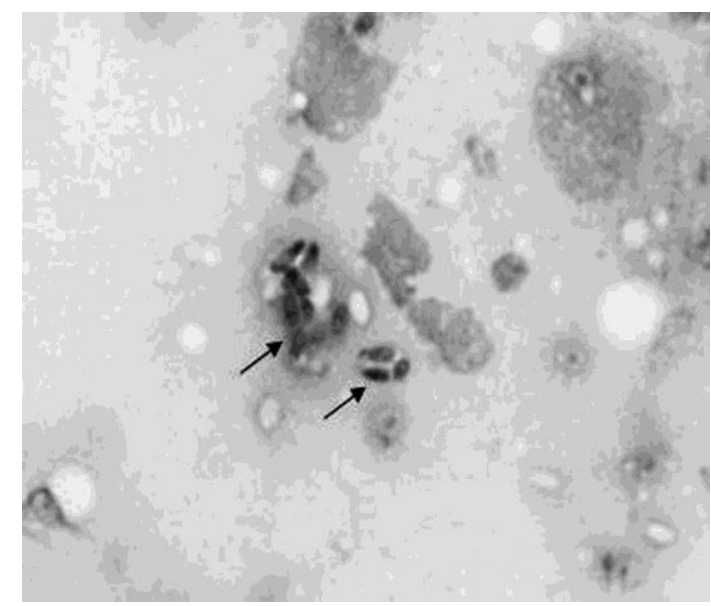

Figura 2. Presença de esporos de Encephalitozoon hellem (setas) em raspado de conjuntiva ocular. Corante panótico rápido (1000x).

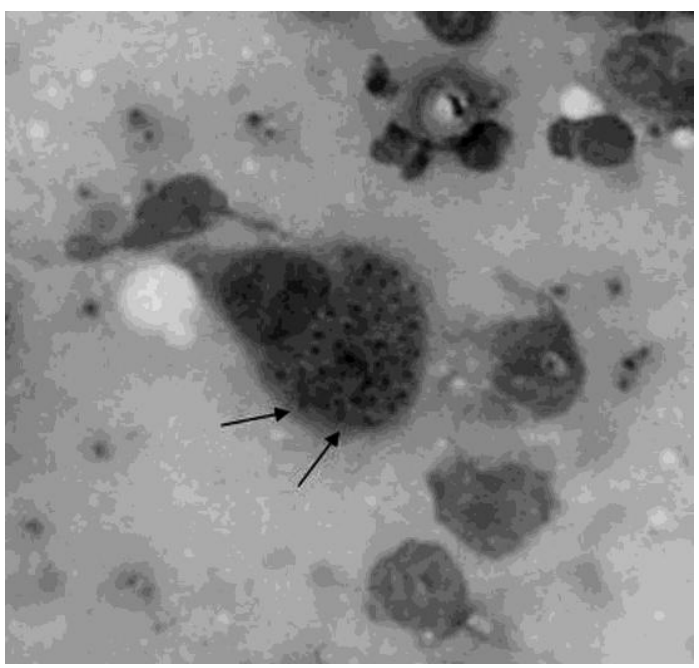

Figura 3. Célula epitelial da conjuntiva ocular com formas evolutivas de Encephalitozoon hellem no citoplasma (setas). Corante panótico rápido (1000x).
Para identificação da espécie de Microsporidium, foi realizada análise molecular, por meio da reação em cadeia de polimerase (PCR) para amplificação de fragmentos do gene da subunidade $18 \mathrm{~S}$ do rRNA. Amostras de raspados de conjuntiva ocular foram usadas para extração de DNA, utilizando-se protocolo de extração com chelex 100, polivinilpirrolidona K-90, isotiocianato de guanidina e sílica ativada, de acordo com Meireles et al. (2007). Para realização da PCR, foram utilizados primers específicos para Enterocytozoon bieneusi - 5' GAA ACT TGT CCA CTC CTT ACG 3' e 5' CCA TGC ACC ACT CCT GCC ATT 3’ ( 607 bp ) (Silva et al., 1996) -, Encephalitozoon intestinalis - 5' TTT CGA GTG TAA AGG AGT CGA 3' e 5' CCG TCC TCG TTC TCC TGC CCG 3’ ( 520 bp) (Silva et al., 1997) e $E$. hellem -, 5' TGA GAA GTA AGA TGT TTA GCA 3' e 5' GTA AAA ACA CTC TCA CAC TCA 3’ ( 547 bp) (Visvesvara et al., 1994), nas seguintes condições de reação: preparação de $25 \mu \mathrm{L}$ de solução contendo $2,5 \mu \mathrm{L}$ de tampão para PCR 1 x, $\mathrm{MgCl}_{2}$ a 2,5mM, 0,5U de Taq DNA polimerase, $\quad 200 \mu \mathrm{M}$ de cada desoxirribonucleotídeo, 200nM de cada oligonucleotídeo (primer), 2,5 $\mathrm{LL}$ de DNA alvo na reação. As amostras foram submetidas à desnaturação inicial do DNA a $94^{\circ} \mathrm{C}$ por $3 \mathrm{~min}$, seguida de 35 ciclos, cada um consistindo em desnaturação a $94^{\circ} \mathrm{C}$ por 30 segundos, 30 s de anelamento a $55^{\circ} \mathrm{C}$ e 90 s de extensão a $72^{\circ} \mathrm{C}$, com extensão final a $72^{\circ} \mathrm{C}$ por $7 \mathrm{~min}$. Após a PCR, as amostras foram submetidas à eletroforese em gel de agarose, observando-se amplificação positiva para E. hellem.

Os fragmentos resultantes da PCR foram purificados com o kit de purificação de DNA "GFX PCR DNA band purification ${ }^{\circledR, " ~(G E ~}$ Health Sciences, Champain, Illinois, EUA), e submetidos ao sequenciamento usando-se o DYEnamic ${ }^{\circledR} \mathrm{ET}$ dye terminator Cycle Sequencing $K_{i t^{\circledR}}$ (GE Health Sciences, Champain, Illinois, EUA). As reações de sequenciamento foram realizadas em sequenciador automático MegaBACE $^{\circledR}$ (GE Health Sciences, Champain, Illinois, EUA), em duplicata e nas duas direções, utilizando-se os primers da PCR.

A determinação das sequências consenso foi realizada por meio do programa Codoncode Aligner v. 2.0.4 (CodonCode Corporation, 
Dedham, Massachusetts, EUA). Após a determinação das sequências consenso, elas foram alinhadas manualmente com auxílio dos programas Clustal W (Thompson et al., 1997) e BioEdit Sequence Alignment Editor (Hall, 1999), tomando-se como base sequências homólogas disponíveis no GenBank. Os resultados indicaram $100 \%$ de similaridade genética com $E$. hellem.

\section{DISCUSSÃO}

Todos os animais avaliados foram positivos para Microsporidium no exame citológico de raspado da conjuntiva ocular, sendo evidenciados esporos e outros estádios evolutivos do parasito. Em humanos com quadros de ceratoconjuntivite, o exame citológico é um dos métodos mais efetivos de diagnóstico de microsporidiose (Rastrelli et al., 1994). Casos de ceratoconjuntivite associados com infecções por E. hellem são encontrados com mais frequência em humanos HIV-positivos, ocasionando infecções oculares ou disseminadas ou, em casos assintomáticos, acometendo o sistema respiratório (Mathis et al., 2005). Em aves, acometimento ocular associado à infecção por Microsporidium já foi detectado em dois casos envolvendo psitacídeos com opacidade de córnea e neovascularização ocular superficial (Canny et al., 1999) e quadro de ceratoconjuntivite crônica não responsiva aos tratamentos convencionais (Phalen et al., 2006).

São poucos os relatos de infecções por E. hellem acometendo aves e, geralmente, estão associados a infecções assintomáticas (Barton et al., 2003), distúrbios gastrintestinais (Black et al., 1997; Snowden e Logan, 1999; Snowden et al., 2001; Carlisle et al., 2002) e renais (Pilparampil et al., 1998). O agente já foi detectado em Psitaciformes (Black et al., 1997; Pilparampil et al., 1998; Barton et al., 2003 Magalhães et al., 2006), Passeriformes (Carlisle et al., 2002; Magalhães et al., 2006), Trochiliformes (Snowden et al., 2001), Columbiformes (Magalhães et al., 2006) e Struthioniformes (Snowden e Logan, 1999).

De acordo com estudo de Barton et al. (2003), suabes cloacais de Agapornis spp. assintomáticos foram colhidos por um período de sete meses e submetidos à detecção de Microsporidium, com prevalência de 25\% em 198 animais analisados.
Entre os animais positivos, 47, 41 e $12 \%$ possuíam, respectivamente, baixa, média e alta quantidade de esporos, evidenciando que aves assintomáticas podem ser portadoras de esporos de E. hellem nas fezes.

Este é o primeiro relato de infecção em aves, por E. hellem, no Brasil. A identificação desse microrganismo em hospedeiros aviários alerta para o potencial papel de aves como portadoras assintomáticas de E. hellem e o risco zoonótico de sua transmissão, de aves de estimação, para os seres humanos. Ainda é importante ressaltar que a microsporidiose deve ser considerada no diagnóstico diferencial para ceratoconjuntivites resistentes às terapias antimicrobianas tradicionais.

\section{REFERÊNCIAS BIBLIOGRÁFICAS}

BARTON, C.E.; PHALEN, D.N.; SNOWDEN, K.F. Prevalence of Microsporidian spores shed by asymptomatic lovebirds: evidence for a potential emerging zoonosis. J. Avian Med. Surg., v.17, p.197-202, 2003.

BLACK, S.S.; STEINOHRT, L.A.; BERTUCCI, D.C. et al. Encephalitozoon hellem in budgerigars (Melopsittacus undulates). Vet. Pathol., v.34, p.189-198, 1997.

CANNY, C.J.; WARD, D.A.; PATTON, S. et al. Microsporidian keratoconjunctivitis in a double yellow headed Amazon parrot (Amazona ochrocephala oratrix). J. Avian Med. Surg., v.13, p.279-286, 1999.

CARLISLE, M.S.; SNOWDEN, K.; GILL, J.; JONES, M. et al. Microsporidiosis in a Gouldian finch (Eythrura (Chloebia) gouldiae). Aust. Vet. J., v.80, p.41-44, 2002.

CURRENT, W.L. Techniques and laboratory maintenance of Cryptosporidium. In: DUBEY, J.P.; SPEER, C.A.; FAYER, R. (Eds). Cryptosporidiosis of man and animals. Boca Raton: CRC, 1990. p.59-82.

DIDIER, E.; DIDIER, P.; FRIEDBERG, D. et al. Isolation and characterization of a new human microsporidian, Encephalitozoon hellem (n. sp.), from three AIDS patients with keratoconjunctivitis. J. Infect. Dis., v.163, p.617621, 1991. 
HALL, T.A. BioEdit: a user-friendly biological sequence alignment editor and analysis program for Windows 95/98/NT. Nucleic Acids Symp. Ser., v.41, p.95-98, 1999.

MAGALHÃES, N.; LOBO, M.L.; ANTUNES, F. et al. Aves e cães como potencial fonte de infecção zoonótica por microsporídeos para o homem. Rev. Port. Cienc. Vet., v.101, p.69-75, 2006.

MATHIS, A.; WEBER, R.; DEPLAZES, P. Zoonotic potencial of the Microsporidia. Clin. Microbiol. Rev., v.18, p.423-445, 2005.

MEIRELES, M.V.; SOARES, R.M.; BONELLO, F. et al. Natural infection with zoonotic subtype of Cryptosporidium parvum in capybara (Hydrocoerus hydrochaeris) in Brazil. Vet. Parasitol., v.147, p.166-170, 2007.

PHALEN, D.N.; LOGAN, K.S.; SNOWDEN, K.F. Encephalitozoon hellem as the cause of a unilateral chronic keratoconjunctivitis in a umbrella cockatoo (Cacatua alba). Vet. Ophthalmol., v.9, p.59-63, 2006.

PILPARAMPIL, N.; GRAHAM, D.; PHALEN, D. et al. Encephalitozoon hellem in two ecletus parrots (Ecletus roratus): identification from archival tissues. J. Eukaryot. Microbiol., v.45, p.651-655, 1998.

RASTRELLI, P.D.; DIDIER, E.S.; YEE, R.W. Microsporidial keratitis. Ophthalmol. Clin. North Am., v.7, p.617-633, 1994.

SILVA, A.J.; SCHWARTZ, D.A.; VIVESVARA, G.S. et al. Sensitive PCR diagnosis of infections by Enterocytozoon bieneusi (Microsporídia) using primers based on the region coding for small-subunit rRNA. $J$. Clinical Microbiol., v.34, p.986-987, 1996.
SILVA, A.J.; SLEMENDA, S.B.; VISVESVARA, G.S. et al. Detection of Septata intestinalis (Microsporidia) Cali et al. 1993 using polymerase chain reaction primers targeting the small subunit ribosomal RNA coding region. Mol. Diagn., v.2, p.47-52, 1997.

SNOWDEN, K.; DAFT, B.; NORDHAUSEN, R.W. Morphological and molecular characterization of Encephalitozoon hellem in hummingbirds. Avian Pathol., v.30, p.251-255, 2001.

SNOWDEN, K.; LOGAN, K. Molecular identification of Encephalitozoon hellem in a ostrich. Avian Dis., v.43, p.779-782, 1999.

SNOWDEN, K.; PHALEN, D.N. Encephalitozoon infection in birds. Semin. Avian Exot. Pet Med., v.13, p.94-99, 2004.

VISVESVARA, G.S.; LEITCH, G.J.; SILVA, A.J. et al. Polyclonal and monoclonal antibody and PCR-amplified small-subunit rRNA identification of a microsporidian, Encephalitozoon hellem, isolated from an AIDS patient with disseminated infection. J. Clin. Microbiol., v.32, p.2760-2768, 1994.

THOMPSON, J.D.; GIBSON, T.J.; PLEWNIAK, F. et al. The Clustal $\mathrm{X}$ windows interface: flexible strategies for multiple sequence alignment aided by quality tools. Nucleic Acids Res., v.24, p.4876-4882, 1997. 